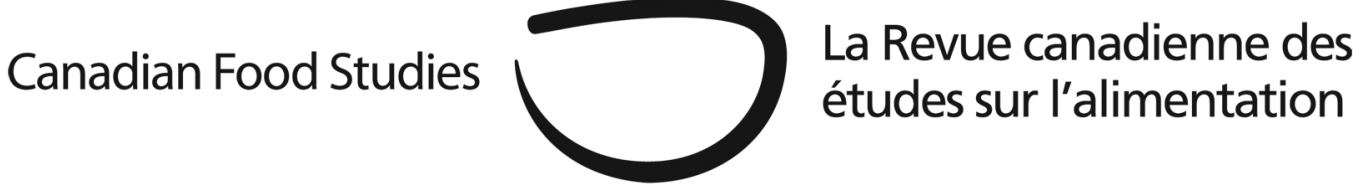

Article de revue

\title{
Pesticides: Le Talon d'Achille des politiques alimentaires canadiennes et québécoises
}

\author{
Marie-Hélène Bacon ${ }^{\mathrm{a}^{*}}$, Louise Vandelac ${ }^{\mathrm{b}}$, et Sébastien Petrie ${ }^{\mathrm{c}}$ \\ a Ph.D. Chercheure au CREPPA ${ }^{1}$, Université du Québec à Montréal (UQAM) \\ b Ph.D. Professeure titulaire, Institut des sciences de l'environnement et Département de sociologie, \\ UQAM, directrice du CREPPA \\ c Ph.D. Chercheur au CREPPA, UQAM
}

\section{Résumé}

Comment expliquer que le projet de politique alimentaire du Canada ignore le dossier des pesticides alors que la récente politique bioalimentaire du Québec évoque vaguement la question, mais sans engagements significatifs? Pourquoi évacuer ainsi l'analyse des enjeux et des effets sanitaires et environnementaux préoccupants des pesticides et notamment du glyphosate, premier pesticide au monde, en croissance exponentielle, qui, déclaré cancérogène probable par le Centre international de recherche sur le cancer (CIRC) de l'Organisation mondiale de la santé (OMS) (IARC, 2015), constitue au Canada 56 pour cent des pesticides agricoles et 44 pour cent de ceux du Québec (Santé Canada, 2017a; MDDELCC, 2017)?

Presqu'omniprésent dans les champs, les cours d'eau agricoles et dans 30 pour cent des aliments au Canada, le glyphosate est l'objet de vives controverses scientifiques et citoyennes dans le monde entier (Robin, 2008, 2018). En Europe, sa ré-autorisation, suite à deux ans de vives controverses a été limitée à 5 ans. Aux États-Unis, 3,500 victimes d’un lymphome non-

\footnotetext{
${ }^{1}$ Cet effort de compréhension des enjeux et des impacts des herbicides à base de glyphosate (HBG), témoigne des recherches du CREPPA, le collectif de recherche écosanté sur les pesticides, les politiques et les alternatives, réunissant une vingtaine de chercheurs-es universitaires de sociologie, biologie, agronomie, médecine, écotoxicologie, anthropologie et phyto-génétique et plusieurs ONG. Ces travaux ont bénéficié de plusieurs subventions de recherche: grands débats de l'Institut Santé et société (ISS-UQAM), Faculté des sciences humaines de l'UQAM (Pafarc1, service aux collectivités et Pafarc2, Alternatives aux pesticides), CIRODD de l'École Polytechnique, RRSPQ (Réseau de recherche en santé des populations), FDE d’Environnement Canada et FRQSC pour équipe émergente.
} 
hodgkinien attribué au Roundup, premier herbicide à base de glyphosate (HBG) en importance au monde, poursuivent en justice son principal fabricant Monsanto (Gonzague \& Michel, 2017) alors qu'en France et en Argentine, des poursuites pour malformations congénitales s'amorcent également contre Monsanto (Foucart, 2018).

Cet article examine, dans une approche interdisciplinaire et intersectorielle, les facteurs de la montée en puissance des HBG, leurs principaux effets sur l'environnement et la santé, et les lacunes d'évaluation et d'encadrement des pesticides, contribuant à leur diffusion massive et à leurs effets. Il met aussi en évidence que les projets et politiques alimentaires canadiennes et québécoises, centrés sur le développement de modèles agro-industriels intensifs et technicisés d'exportation soumis à une conception de croissance économique, sont peu compatibles avec les exigences de protection de la biodiversité, de la santé et de la sécurité alimentaire. Or, dans un contexte de globalisation des marchés et d'accords de libre-échange avec l’Europe, plus soucieuse du Principe de Précaution et de droits des consommateurs, la négligence de ces enjeux écologiques et sanitaires risque d'en constituer le talon d’Achille.

Mots clés: pesticides, herbicides, glyphosate, politiques publiques, politique alimentaire, politique bioalimentaire, santé, environnement, Canada, Québec

\section{Introduction}

Bien que le Canada ait ré-homologué le glyphosate 6 mois avant l’Union Européenne, il a pris sa décision en toute connaissance de cause. Déjà en 2015, le CIRC de l’OMS avait déclaré le glyphosate, cancérogène probable chez l'humain (IARC, 2015). Et le Canada ne pouvait guère ignorer les scandales sanitaires plombant la réputation de Monsanto, notamment les 20000 victimes des BPC d'Anniston aux États-Unis et celles de l'agent orange utilisé comme défoliant au Vietnam. Il ne pouvait ignorer non plus les nombreuses accusations de propos mensongers, de manipulations et d'études inconsistantes voire fallacieuses, ni les documentaires et livres d'enquêtes de Marie-Monique Robin, Le Monde selon Monsanto (2008), Notre Poison quotidien (2011) et Le Roundup face à ses juges (2017), diffusés à des millions de personnes, et qui avaient déjà contribué à transformer "une marque commerciale en marque de disgrâce" (Vandelac, 2018). En outre, à l’hiver 2017, filtraient déjà les informations sur les Monsanto Papers et s’organisait, en Europe, l’opposition citoyenne de plus de 1,3 millions de personnes au renouvellement du glyphosate.

La double toxicité, au sens propre et figuré, des HBG et du Roundup de Monsanto était un secret de polichinelle. Rappelons qu'un brevet émis en 1964 qui en fait un précurseur de chélateur de métaux, avant que le glyphosate soit utilisé en 1974 comme principe dit actif de formulations commerciales d'HBG comme le Roundup et qu'il soit breveté en 2010 comme antibiotique, aux effets suspectés pour le microbiome (Mao et al., 2018). Le glyphosate n'est jamais utilisé seul dans les champs mais bien inclus dans des formulations commerciales très 
rarement analysées par les instances réglementaires (Séralini, 2015). Or, plusieurs études ont mis en évidence que les co-formulants de 8 des 9 principaux pesticides au monde seraient jusqu'à 1000 fois plus toxiques que l'ingrédient dit actif dont les effets peuvent être observés en deçà des seuils réglementaires (Mesnage, Defarge, Spiroux de Vendômois, \& Séralini, 2014, 2015). En outre, les effets observés lors d'études animales de perturbation endocrinienne et de dommages au foie et aux reins, ainsi que les impacts étudiés sur la dégradation des sols et de la biodiversité figurent parmi les effets des HBG.

Ces risques ont-ils été pleinement pris en compte par le principal fabricant et par les instances évaluatives et réglementaires? Rappelons que "les réglementations américaines et européennes ne demandent aux industriels aucune étude sur les effets sanitaires à long terme” (Horel \& Foucart, 2017). Or, les effets chroniques se manifestent à long terme. En outre, soulignait une toxicologue en chef de Monsanto en novembre 2013, "Vous ne pouvez pas dire que le Roundup n’est pas cancérogène, car nous n’avons pas fait les tests nécessaires pour le dire ” (Foucart \& Horel, 2017).

Au sens figuré, la toxicité des HBG est révélée par les “Monsanto Papers ” témoignant des stratégies de camouflage et de désinformation de la firme, qui, pour éviter d'ébruiter la dangerosité du Roundup, interfèrent avec les processus d'évaluation scientifique, et empoisonnentles règles élémentaires de la science, de la démocratie et de l’évaluation réglementaire au profit d’intérêts industriels (McHenry, 2018). Ces milliers de documents internes de la firme, rendus publics par la justice américaine, dans la foulée des poursuites contre Monsanto de plus de 3500 victimes d'un lymphome non-hodgkinien attribué à ce désherbant (Gonzague \& Michel, 2017), ont fait la une des médias européens et nord-américains (Foucart \& Horel, 2017, 2017a, 2017b, 2017c; Foucart, 2017; Gillam, 2017). Ils ont mis en évidence les stratégies de Monsanto pour présenter comme indépendantes des études scientifiques co-rédigées par des salariés de la firme (Lesnes, 2018), pour utiliser le nom de scientifiques "ghost-writer" pour signer des articles écrits par des employés de Monsanto, pour miner la réputation de chercheurs indépendants et orchestrer le retrait d'un article scientifique sur les effets nocifs du Roundup, rémunérant au passage le directeur de la revue où on a retiré l'article (Foucart, 2017; Gillam, 2018; Krimsky \& Gillam, 2018).

Les allégations d'ingérences dans l'évaluation scientifique et gouvernementale ont même valu aux lobbyistes de Monsanto, le 28 septembre 2017, suite à leur refus de comparaître pour s'expliquer à ce sujet, de se voir retirer par les parlementaires leur droit d'accès au Parlement Européen, un évènement sans précédent (Neslen, 2017). C’est par ailleurs le lendemain de la publication dans Le Monde du plagiat des instances d'évaluation européenne, reprenant presque mot à mot des documents de Monsanto, que l’Union Européenne a renouvelé de justesse, le 27 novembre 2017, le glyphosate, et pour 5 ans seulement. Cette décision a fait suite au vote inattendu, contre son propre gouvernement, du ministre allemand de l'Agriculture, alors que la France, l'Italie, la Belgique et l'Autriche voulaient limiter l'autorisation à 3 ans (Foucart \& Horel, 2017). 
Bien que les agissements de Monsanto, principal producteur d’HBG aient été largement documentés depuis plus d'une décennie (Séralini, Mesnage, Defarge \& Spiroux de Vendômois, 2014; Séralini, 2005; Robin, 2008, 2018), et bien que la présence croissante de ces pesticides dans les cultures, les sols, les eaux et aussi dans le corps humain, via leurs résidus dans les aliments, constitue un problème de taille, paradoxalement Agriculture et Agroalimentaire Canada (AAC) n'a même pas évoqué le dossier des pesticides lors du lancement de ses consultations sur Une politique alimentaire pour le Canada, un mois après la décision de l'ARLA.

Devant le scandale sanitaire sur la santé publique et sur l’intégrité de la recherche révélés par les “Monsanto Papers”, comment expliquer que des instances responsables comme Santé Canada aient fait l'impasse sur des pratiques aussi contraires à l'éthique scientifique, au risque d'éroder la crédibilité même des dispositifs publics et d'accroître la méfiance des citoyens. Et comment, vu les risques pour l'environnement, la santé et l'alimentation de la hausse exponentielle du principal pesticide en usage au Canada, les responsables de la politique alimentaire canadienne ont-ils pu balayer ainsi du revers de la main, un dossier aussi crucial pour une alimentation viable? Cela est d'autant plus étonnant que la politique alimentaire canadienne vise, en écho au Rapport Barton (2017), une forte hausse des exportations agricoles du Canada, ce qui risque de se heurter aux exigences des partenaires d'Europe, sans doute peu enclins à avaler les couleuvres des importations alimentaires gavées au glyphosate, après en avoir limité le renouvellement sur leur territoire.

\section{La sécurité alimentaire ne repose pas sur les pesticides}

Ces questions touchent désormais le monde entier. Quelques mois avant les débuts de la consultation d'AAC fin janvier 2017, l'influence indue des multinationales sur les gouvernements et sur leur encadrement des pesticides avait été vertement critiquée par le Rapport conjoint de la Rapporteuse spéciale sur le Droit à l’alimentation aux Nations-Unies écrit en collaboration avec le Rapporteur spécial sur les incidences sur les droits de l’Homme de la gestion et de l'élimination écologiquement rationnelles des produits et déchets dangereux (Nations Unies, 2017). Selon ces auteurs-es, “L’affirmation de l'industrie agrochimique selon laquelle les pesticides sont nécessaires pour assurer la sécurité alimentaire est aussi inexacte que dangereusement fallacieuse” (Ibid, p.22). Ils ajoutent, “Les pesticides, dont l'usage fait l'objet d'une promotion agressive, posent un problème du point de vue des droits de l'Homme à l'échelle de la planète, et leur utilisation peut avoir de très graves répercussions sur l'exercice du droit à l'alimentation” (Ibid, p.3). Ce rapport, rappelant que "les doses d'utilisation ont considérablement augmenté au cours des dernières décennies”, ajoutait que dans le monde, les pesticides seraient à "l’origine de 200000 décès par intoxication aiguë chaque année au total, dont 99 pour cent surviennent dans les pays en développement” (Ibid, p.3).

Ce rapport faisait alors échos à plusieurs autres documents émanant de grandes agences internationales traitant des problèmes majeurs au sein des secteurs agricole et alimentaire, tout en 
mettant en évidence les écueils de ces politiques et modes de production. Ainsi, un groupe international d'experts sur les systèmes alimentaires durables soutenait que " the modern agriculture is failing to sustain the people and resources on which it relies, and has come to represent an existential threat to itself.” (IPES Food, 2016, p.9). Plus récemment, le Directeur général de la FAO soulignait que :

L’agriculture est aujourd'hui parvenue à un tournant décisif. Le modèle agricole dominant actuellement appliqué est extrêmement problématique, non seulement en raison des dommages occasionnés par les pesticides, mais aussi de par l’incidence de ces produits sur les changements climatiques, la réduction de la biodiversité et l'incapacité de ce modèle à assurer la souveraineté alimentaire. (Nations Unies, 2017, p.25)

Le rapport Perspectives territoriales mondiales de la Convention des Nations-Unies sur la lutte contre la désertification (CNULCD), ajoutait que le "modèle actuel de l'agro-industrie profite à quelques-uns aux dépens de beaucoup”. Or, avec des “terres dégradées et polluées axées sur les rendements à court terme" et les "schémas actuels de production, de distribution et de consommation alimentaires”, un consensus émerge, celui d'un système alimentaire brisé et inefficace menaçant la santé humaine et la durabilité environnementale (UNCCD, 2017, p.8).

Dans ce contexte, le Canada, soucieux d'une image internationale avant-gardiste mais avide consommateur de pesticides, va-t-il faire prévaloir, pour des décennies encore, une conception agroindustrielle, centrée sur de grandes monocultures d'exportations à base de pesticides, jugées dépassées en raison de leurs ravages sur la santé, l’environnement et la vitalité rurale, comme l’évoquait déjà en 1962, Silent Spring de Rachel Carson?

\section{Un secteur agroalimentaire, réduit au rôle de "moteur de croissance économique"?}

La consultation sur la politique alimentaire canadienne, et notamment les termes mêmes du sondage auprès de la population, confirment la primauté d’objectifs économiques, centrés sur le développement des marchés d'exportations, tout en reléguant au second plan une “ vision à long terme pour la réalisation des objectifs sanitaires, environnementaux, sociaux et économiques en matière d'alimentation ” (Gouvernement du Canada, 2017a). Cela conforterait les tendances actuelles, où la valeur des exportations des cultures agricoles canadiennes a doublé au cours des dix dernières années, pour dépasser, en 2016, les 24 milliards de dollars, auxquels s’ajoutent deux milliards de dollars liés aux exportations de pesticides, d'engrais et autres produits chimiques agricoles, destinées à 97 pour cent aux États-Unis (Gouvernement du Canada, 2017).

L'actuel projet de politique alimentaire canadienne propose donc, et c'est là l'un des quatre thèmes du sondage de la consultation publique, de profiter d'une hausse de la demande pour soutenir l’innovation et accroître les exportations afin de devenir un "fournisseur 
alimentaire” à l'échelle mondiale (Gouvernement du Canada, 2017a). Comment envisager de telles perspectives, quand le soutien réel du Canada à ses agriculteurs est l'un des plus faibles des pays de l'OCDE, soit 0,4 pour cent du PIB en comparaison de 0,7 pour cent en moyenne, et que les modalités d'attribution encouragent notamment la surconsommation d'intrants, souligne un récent rapport de l'OCDE (Desrosiers, 2018). En outre, ces perspectives d'exportation massive tranchent quelque peu d’avec les réflexions sur la sécurité alimentaire exigeant de préserver les cultures de proximité et refusant de réduire la production alimentaire à une simple marchandise comme les autres (Benhammou, 2009 ; FAO, 2015).

Le projet de politique évoque certes l'importance d'aliments sains, nutritifs et de qualité supérieure pour tenter de mettre en valeur la réputation du Canada et son rôle dans le développement des marchés internationaux. Cependant, l'étroite conception de la salubrité et du caractère nutritif des aliments, ignorant les usages massifs de pesticides et d'antibiotiques donnés aux animaux, et leurs effets sur la biodiversité, ainsi que l'absence d'étiquetage clair et complet ne passe pas inaperçue, notamment dans les marchés européens. En témoigne ces extraits du Rapport de la commission indépendante (Angot et al., 2017) sur L'impact de l'Accord Économique et Commercial Global entre l'Union européenne et le Canada (AECG/CETA) sur l'environnement, le climat et la santé, remis le 7 septembre 2017 au Premier ministre de la France.

Du côté canadien, en dépit de la montée des préoccupations environnementales depuis le début des années 2000, la protection de l'environnement n'est pas encore au coeur de la politique agricole canadienne et les exigences environnementales demeurent bien moindres que dans l’UE... le Canada se situe loin derrière les États-Unis, l’Union européenne ou l'Australie en ce qui concerne les lois et politiques environnementales, qu'il s'agisse de la qualité de l'eau et de l'air, des pesticides et substances toxiques, du changement climatique ou de la biodiversité. Pour les pesticides, le Canada autorise encore 46 substances actives qui ont été interdites depuis longtemps dans les autres pays. (p. 46)

La politique bioalimentaire du Québec, conçue d’abord comme outil de développement économique pour l'agroalimentaire, les pêcheries, les industries de transformation et les détaillants (MAPAQ, 2016, 2016a, 2016b), et visant surtout à arrimer les besoins de croissance des entreprises avec les consommateurs et à développer de nouveaux marchés, a-t-elle pris en compte les exigences en vigueur en France et en Europe? Les conceptions “d'environnement” servent-elles d’abord d'argument de “verdissement promotionnel” pour se démarquer des compétiteurs? Et comment les perspectives santé, centrées sur la salubrité des produits, peuventelle ignorer l'approche globale et intégrée de ces enjeux? D’ailleurs, les documents de consultation n'évoquent pas les préoccupations sanitaires ou environnementales pour encourager le développement de l'agriculture biologique, mais essentiellement son rôle de nouveau créneau 
de croissance économique...(MAPAQ, 2016, 2016a). De même, si la politique bioalimentaire reconnaît les préoccupations des consommateurs soucieux de réduire les impacts nocifs des pesticides (MAPAQ, 2018), et projette d'accroître le soutien pour doubler les cultures biologiques de 2 pour cent à 4 pour cent (Ibid, p.18), néanmoins aucune mesure significative ne permet ni de diversifier les pratiques agricoles, ni de réduire les principaux pesticides en usage.

Au Canada comme au Québec, les projets et les politiques alimentaires demeurent, en dépit de prétentions d’innovations, centrés sur des modèles de monocultures à engrais et pesticides, destructrices des sols, de la biodiversité et de la qualité de l'eau, en plus d'accentuer les changements climatiques, bref des modèles, qui souvent couplés à la production animale intensive, voient leur viabilité profondément remise en question (Nations Unies, 2017; UNCCD, 2017; IPES Food, 2016). En dépit de vertueux discours sur la santé et l'environnement, ces projets et politiques alimentaires, menés à l’ombre des multinationales des semences, des OGM et des pesticides, dont ils confortent l'influence, risquent fort, dans un contexte d'accords de libre-échange avec l'Asie et avec l'Europe, de contribuer à la prolifération croissante des pesticides. Par ailleurs, si, comme l'y autorise la CETA, l'exportation de porc du Canada vers l'Europe était multipliée par 13, on risquerait fort, pour nourrir ces animaux et absorber les lisiers, de multiplier les cultures de maïs et de soja transgéniques, gavés d’HBG et d'aggraver les problèmes liés (Angot et al., 2017).

\section{Hausse exponentielle des ventes de pesticides dans le monde et au Canada}

La vente de pesticides dans le monde, en constante augmentation, particulièrement depuis les deux dernières décennies, a atteint 3.5 milliards de kg d’ingrédients actifs (kg i.a.) par année dans les années 2010, la Chine, les États-Unis et l'Argentine utilisant alors près de 70 pour cent de ces pesticides (Pretty et Pervez Bharucha, 2015, p.154).

Le Royaume-Unis, l’Italie et même la France et le Danemark, grands consommateurs de pesticides ont réduit de façon marquée leur utilisation, suite notamment à des changements de politiques (Pretty et Pervez Bharucha, 2015, p.154). Le Canada, pour sa part, suit un mouvement inverse au point d'avoir enregistré une hausse de 157 pour cent des ventes de pesticides dans le secteur agricole entre 1994 et 2014 (OECD, 2013, 2017), un secteur où se concentraient 74.3 pour cent des pesticides en 2014, en hausse de 14 pour cent depuis 2008, première année de publication des statistiques sur les ventes de pesticides au Canada (Santé Canada, 2017a, 2011).

Le Canada a même homologué 1000 nouveaux pesticides entre 2008 et 2014 pour en compter 6866 en 2014 (Santé Canada, 2017a, 2011). Cependant, 10 ingrédients actifs seulement, dont le glyphosate trônant depuis 2008 à la première place des ingrédients actifs de pesticides les plus vendus au Canada, constituaient 66 pour cent des 101 millions de kg. i.a. de pesticides vendus en 2014 au Canada (Santé Canada, 2017a, p.2), témoignant d'une forte concentration des ingrédients vendus et des firmes impliquées. 
On observe les mêmes tendances au Québec, avec une forte hausse des ventes de pesticides agricoles depuis 1992, sur des surfaces agricoles en constante diminution. Selon le plus récent bilan des ventes de pesticides du Québec, les ventes de pesticides agricoles, estimées à près de 4 millions de kg i.a. en 2015, en hausse de 32 pour cent depuis 2006, représentaient alors 87.5 pour cent des ventes totales de pesticides (MDDELCC, 2017). Or, ces ventes de pesticides, tant au Canada qu’au Québec, demeurent largement dominées depuis plus de 10 ans, par les herbicides à base de glyphosate.

\section{Applications massives d'herbicides à base de glyphosate (HBG)}

Au Canada, les herbicides représentent, depuis 2008, près de 80 pour cent des pesticides utilisés dans le secteur agricole, une hausse de 39 pour cent, entre 2008 et 2014, signifiant des ventes additionnelles de plus de 16 millions kg i.a. en 2014 (Santé Canada, 2017a, 2011). Ce marché est largement dominé par les herbicides à base de glyphosate (HBG) qui représentaient, en 2014, 56 pour cent de tous les pesticides vendus dans le secteur agricole et 71.5 pour cent (42 $286074 \mathrm{~kg}$ i.a.) de tous les herbicides vendus au Canada (Santé Canada, 2017a). Non seulement constituentils les herbicides les plus utilisés au Canada mais également ceux dont les ventes ont aussi le plus fortement augmenté depuis 2008 (Graphique 1).

Graphique 1 : Évolution des ventes totales de pesticides et d'herbicides pour le secteur agricole, et de glyphosate* au Canada entre 2008 et 2014 (millions kg m.a.)

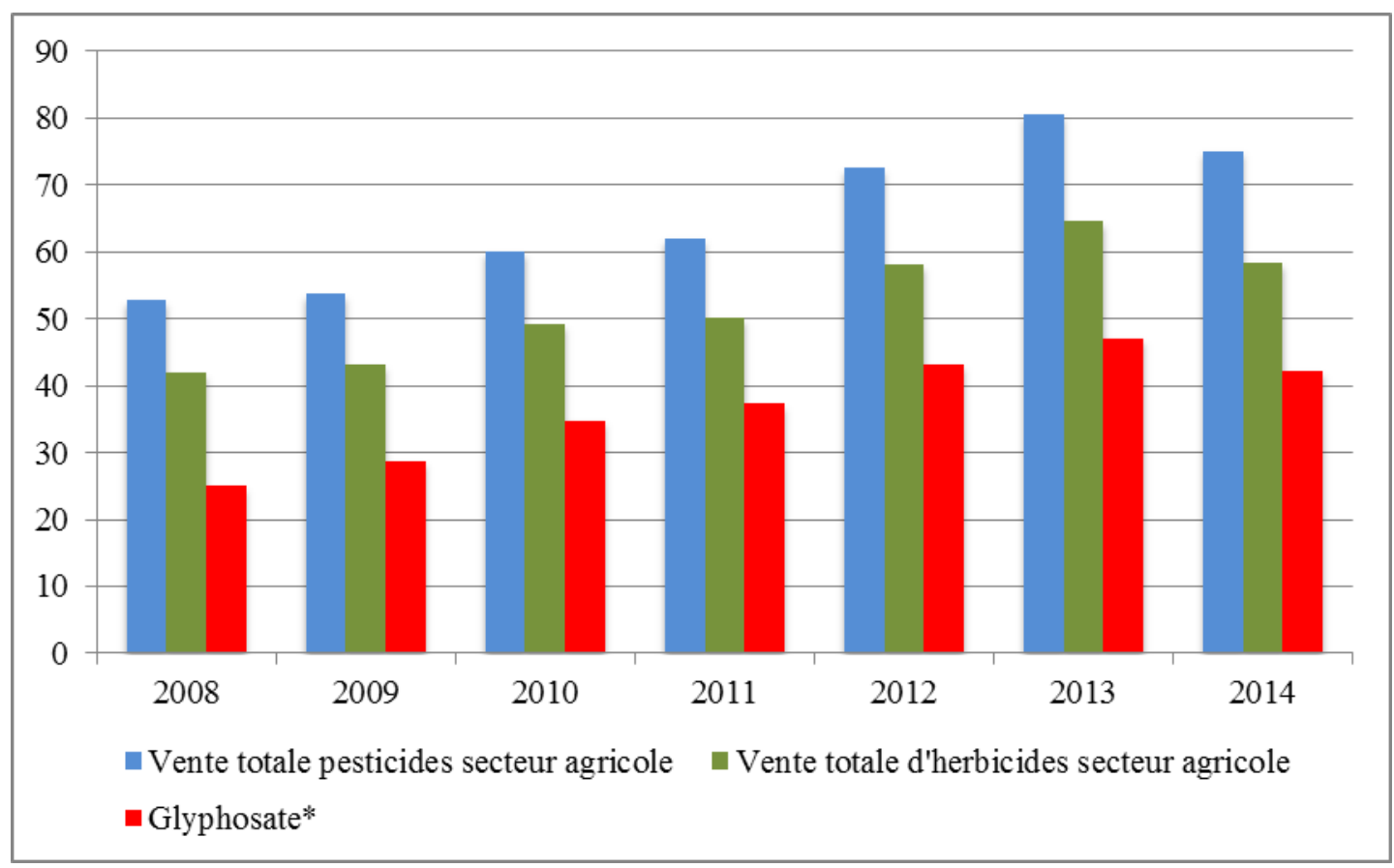

Source: Santé Canada, Rapports sur les ventes de produits antiparasitaires.

*Données pour le groupe des “ acides phosphoniques et dérivés “ principalement constitué des HBG 
Le Québec n’échappe pas à une utilisation croissante des herbicides qui représentaient, en 2015, plus de 65 pour cent des ventes de pesticides. Les ventes d'HBG, en hausse de 60 pour cent entre 2006 et 2015 (Graphique 2), constituaient alors 44.2 pour cent (1 655422 kg i.a.) des ventes de tous les pesticides agricoles (MDDELCC, 2017, Milieu agricole et annexe 1).

Ceci dit, les données sur les épandages d’HBG sont très partielles, en raison des lacunes majeures du Bilan des ventes et de données ne portant que sur le glyphosate qui ne représente qu'environ 40 pour cent des formulations commerciales d'HBG (Douzelet et Séralini, 2018). Les quantités totales de pesticides appliqués sont alors considérablement sous-estimées ainsi que leurs cascades d'effets dans les sols, l'eau, la faune, la biodiversité et la santé, d'autant plus, que ces effets se manifestent à des doses nettement inférieures à celles des limites réglementaires (Mesnage et al., 2015).

Graphique 2: Évolution des ventes de glyphosate* au Québec entre 1992 et 2015 (millions de kg m.a.)

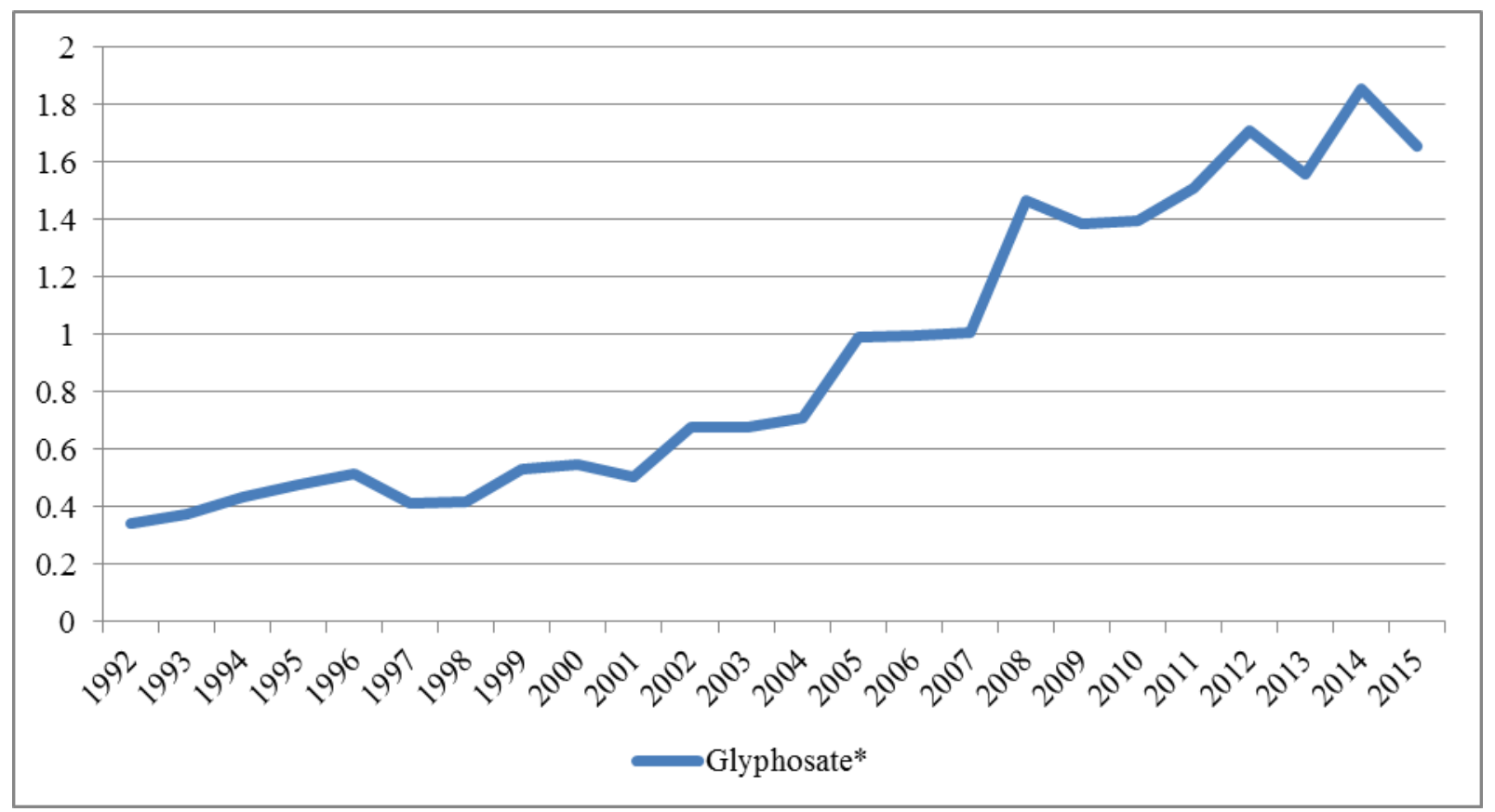

Sources : Gorse et Balg, 2012 et 2014 ; Gorse et Dion, 2007 ; MDDELCC, 2016 et 2017

* Données pour le groupe des “ acides phosphoniques et dérivés “ principalement constitué d’HBG.

Sans prendre en compte tous ces éléments, le Vérificateur général du Québec a néanmoins conclu, dans son rapport sur les pesticides en milieu agricole, que les stratégies gouvernementales des 25 dernières années pour réduire les usages des pesticides et leurs impacts sanitaires et environnementaux, constituaient de cuisants échecs (Leclerc, 2016). Ce rapport soulignait l'augmentation continue des ventes de pesticides agricoles ainsi que la hausse de près de 30 pour cent, entre 2006 et 2014, des indicateurs de risque pour la santé et l'environnement qui y étaient associés (Ibid, P.7). Parmi les raisons invoquées de tels échecs: l’absence d'application de l'éco-conditionnalité lors du versement d'aides financières aux agriculteurs et 
l'insuffisance voire l’inefficacité des stratégies du MAPAQ “pour amener les agriculteurs à adopter des pratiques agricoles favorables au développement durable et pour faire contrepoids à l’industrie agrochimique qui influence fortement le marché” (Ibid, p.22).

Rappelons à grands traits qu'en 1992, le ministère québécois de l’Agriculture, des Pêcheries et de l'Alimentation (MAPAQ) s'était engagé, dans sa première stratégie phytosanitaire, à réduire de 50 pour cent l'usage des pesticides agricoles avant 2000, une tentative depuis qualifiée d'échec. La Politique nationale de l'eau (2002), visant à encourager, avant 2010, une réduction de la pression environnementale liée à l'usage des pesticides en milieu agricole, ne fût guère plus concluante. La stratégie dite “phytosanitaire”, adoptée pour l’horizon 2011-2021, ne visait plus à réduire de 50 pour cent les quantités de pesticides, mais à réduire de 25 pour cent les risques des pesticides pour la santé et l'environnement d’ici 2021. Or, bien que les HBG constituent 44 pour cent des pesticides agricoles en usage au Québec, ils ont été exclus de cette stratégie ainsi que de la Stratégie québécoise de réduction des pesticides 2015-2018 (MDDLECC, 2015) et des nouvelles modifications réglementaires (MDDLECC, 2018).

Ces récentes modifications réglementaires prétendent réduire l'utilisation de 5 pesticides jugés toxiques, soit l'atrazine interdite en Europe depuis 14 ans, le chlorpyrifos aux effets neurotoxiques avérés et seulement 3 des nombreux néocotinoïdes tueurs d’abeilles, en rendant obligatoire leur prescription par un agronome. Permettre à des agronomes, non formés en santé environnementale, et dont une proportion significative travaille pour l'industrie des pesticides, d'autoriser, pour des raisons agronomiques, des pesticides jugés nocifs pour l'environnement et la santé s’annonce être une mesure pour le moins limitée. D’autant plus que l’on observe déjà une utilisation accrue de Dicamba et de 2,4-D, herbicides très toxiques, en complément des HBG, notamment pour tenter de limiter les problèmes de plantes résistantes résultant de la hausse constante des épandages d’HBG, un phénomène déjà bien connu aux États-Unis où les épandages d’HBG ont été multipliés par 15 entre 1996 et 2014, et où les deux-tiers des applications d'HBG y ont été réalisées au cours des dix dernières années (Myers et al., 2016).

Selon Charles Benbrook, agronome américain et ancien directeur de la division agricole de l'Académie nationale des sciences pendant 7 ans: "In the U.S., no pesticide has come remotely close to such intensive and widespread use” (Benbrook, 2016, p.1). Les cartes cidessous illustrent d'ailleurs la progression et l'ampleur de ces épandages aux États-Unis entre 1992 et 2015 (Figure 1).

Comme en témoignent ces cartes, les fortes concentrations d'HBG dans les zones agricoles des tributaires se jetant dans les Grands Lacs, auxquelles on pourrait ajouter les concentrations massives d'Atrazine, toujours autorisée aux États-Unis, invitent à vérifier l’hypothèse des impacts potentiels de ces épandages massifs sur la qualité des eaux des Grands lacs et possiblement celles du Saint-Laurent, objet éventuellement d'examen par la Commission mixte internationale. 
Figure 1: Augmentation des épandages d'HBG en agriculture aux États-Unis entre 1992 et 2015
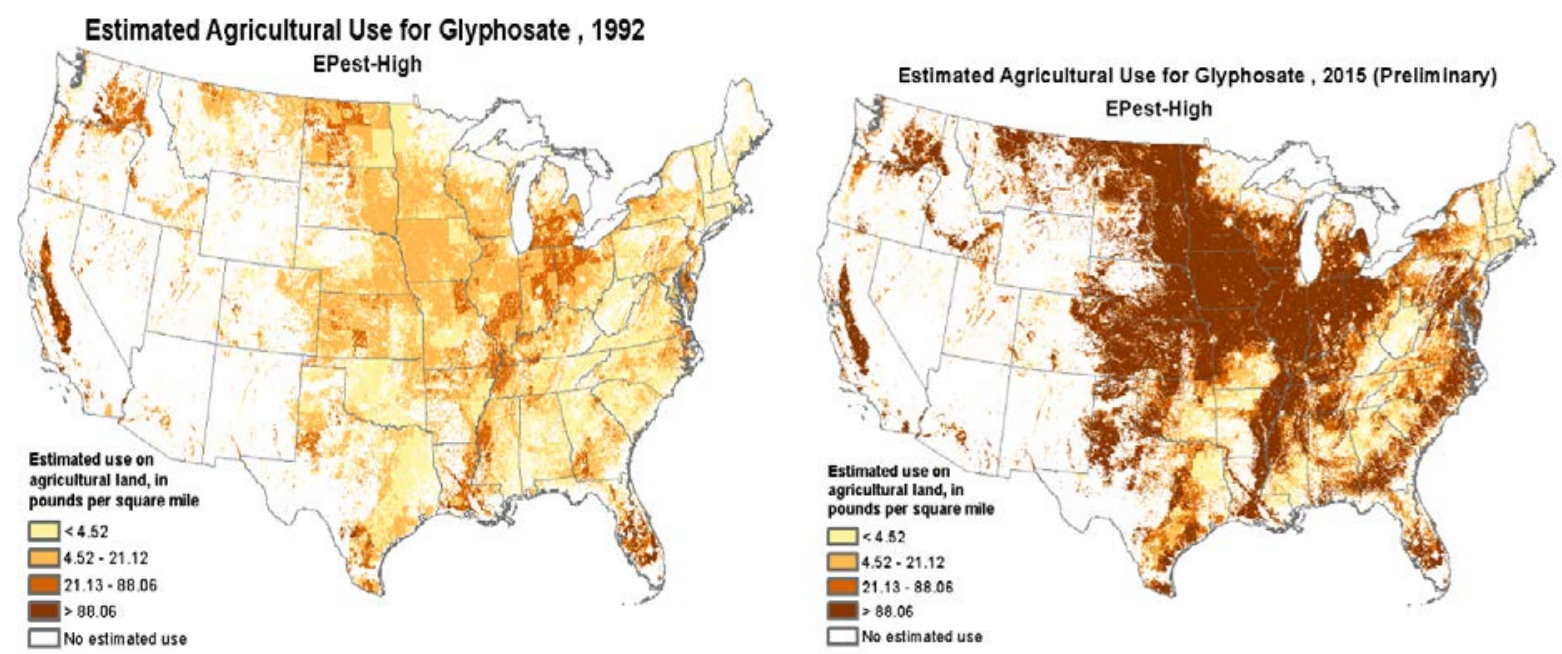

Source: USGS, 2017 (Ces cartes sont une gracieuseté du U.S. Geological Survey / Maps courtesy of the U.S. Geological Survey)

\section{Usages accrus d'HBG: pour les OGM mais aussi pour tout, partout et en tout temps}

Cette très forte hausse des ventes d'HBG en Amérique du Nord et de leurs épandages dans l'environnement résulte de facteurs structurels parmi lesquels on compte l'autorisation des OGM et la multiplication des formulations commerciales, des usages et des périodes d'utilisation des HBG.

Depuis 1996, la diffusion des semences génétiquement modifiées (GM) de maïs, soja et canola, conçues dans près de 75 pour cent des cas pour absorber des HBG sans en mourir ou encore pour produire leur propre insecticide, a largement contribué à la hausse des ventes d'HBG. Les superficies de cultures GM sont passées en 20 ans, de 2 millions à 185 millions d'hectares en 2016 (ISAAA, 2016, p.3). La majorité (89 pour cent) des cultures GM dans le monde sont concentrées en Amérique, d’abord aux États-Unis, avec 72.9 millions d'hectares en 2016, représentant 39 pour cent des superficies mondiales, puis au Brésil, en Argentine et au Canada (Ibid, p.5). Le Canada, considérant les OGM comme un “ moteur de croissance économique ”, en a fortement encouragé les développements, et se plaçait au 4ième rang mondial en 2016 avec 11.6 millions d'hectares de cultures GM, soit 6 pour cent des superficies mondiales (Ibid, p.5).

Or, l'utilisation des HBG va de pair avec les cultures GM. Ainsi, aux États-Unis, "Genetically engineered herbicide-tolerant crops now account for about 56 pour cent of global glyphosate use ” (Benbrook, 2016, p.1). Les OGM agricoles de soja, maïs et canola, sont non seulement conçus pour tolérer des HBG, mais en outre les doses annuelles maximales de HBG qui y sont autorisées par l'Agence de réglementation de la lutte antiparasitaire (ARLA) sont de 
17 pour cent à 25 pour cent plus élevées que dans les cultures non GM (ARLA, 2015, Annexe IIa).

Or, en autorisant les cultures GM et en haussant les seuils d'épandages d'HBG, on a accru à 35 le nombre de plantes résistantes à ces herbicides (Benbrook, 2012; Heap, 2018; Robin, 2018). Cette spirale toxique, marquée par la hausse des épandages d’HBG, la multiplication de plantes résistantes, le recours à d'autres herbicides toxiques comme le 2,4-D et le Dicamba, oblige certains agriculteurs américains, victimes d'infestations de plantes invasives comme l'amarante géante, à abandonner certaines cultures aux mauvaises herbes (Robin, 2018).

Autre élément clef, les pouvoirs publics ont progressivement multiplié le nombre d’homologations de formulations à base de glyphosate et les usages autorisés. Ainsi, au Canada, le nombre de nouveaux produits est passé, de mai 2012 à mai 2017, de 169 à 189 produits alors que 13 autres sont en cours d'homologation (ARLA, 2015, 2017). En agriculture, les HBG sont utilisés dans les cultures de céréales, de légumineuses et de petits fruits, trois secteurs importants de production et d'exportation, ainsi que dans le maraîchage (ARLA, 2015, pp. 71-92). Ces usages sont désormais étendus à toutes les périodes de culture, avant les semis, au moment de la levée, à la pré-récolte et lors de la post-récolte, si bien que ces HBG se retrouvent alors de façon quasi continue dans les cultures et les sols, dans les réseaux hydriques et les aliments.

L’ARLA a également autorisé l'utilisation de ces herbicides à large spectre à peu près partout, allant des pâturages, aux forêts, aux boisés et aux emprises de chemin de fer, en passant par les cultures d'arbres de Noël et de plantes ornementales, autant de menaces à la biodiversité, dont les effets cumulatifs peuvent s’avérer redoutables. Ainsi, la destruction des habitats par l'urbanisation mais aussi par la multiplication des grandes monocultures, ajoutés aux usages massifs de pesticides, détruisant “ mauvaises herbes ”, pollinisateurs, insectes et autres organismes jugés nuisibles, dégradent des pans entiers de la biodiversité et affectent toute la chaîne alimentaire, ce qui expliquerait qu'au Canada 61 pour cent des populations d'oiseaux champêtres ont été décimés en 40 ans, et que 1,2 million d’oiseaux par année succombent (Marceau, 2017).

Autre exemple éloquent, au Nouveau-Brunswick des HBG ont été abondamment pulvérisés sur des terres de la Couronne, pour entraver la croissance des arbres feuillus et favoriser ainsi la croissance des résineux, convoités pour nourrir les moulins des industries de pâtes à papiers (Livesey, 2017). Ces usages massifs d'HBG seraient responsables de la chute drastique de la population de chevreuil qui de 286,000 têtes au milieu des années 1980, serait tombée aujourd'hui à 70,000, suite à la destruction, par les HBG, des feuillus dont ils se nourrissent (Ibid). Selon certains observateurs, l'entente de 25 ans d'exploitation forestière intensive sur les terres de la Couronne, signée en 2014, avec J.D. Irving Ltd., magnat du pétrole, contrôlant aussi les plus importantes compagnies forestières de la région, risque d’anéantir complètement les chevreuils (Ibid). C’est pourquoi 35,000 personnes ont signé trois pétitions remises au parlement du Nouveau-Brunswick et que des citoyens ont fait des représentations au 
sujet des impacts des HBG auprès de la Ministre canadienne de la Santé, députée fédérale de la circonscription de Moncton-Riverview-Dieppe.

\section{Qui dit hausse des usages, dit hausse des résidus}

La hausse marquée des quantités d’HBG pulvérisé dans l'environnement se traduit également par une contamination accrue des sols, des cours d'eau et des aliments, principales sources d'exposition humaine à ces herbicides (Leclerc, 2016; Myers et al., 2016). Le gouvernement canadien a établi des limites maximales de résidus (LMR) de glyphosate pour les aliments visant, dit-on, à minimiser les risques potentiels pour la santé. Or, tout porte à croire que ces LMR sont plutôt établis en fonction des pratiques agricoles, du niveau de contamination par les pesticides ainsi que des marchés d'importations et d'exportations et parfois même des vœux de certaines firmes.

Il n’existe pas de normes internationales unifiées quant aux limites maximales de résidus de glyphosate retrouvés dans les aliments. Et manifestement, pas de normes non plus sur le nombre et sur les effets cocktails de pesticides et de leurs résidus si le gouvernement fédéral autorise des résidus de 90 pesticides différents sur le blé et de 115 sur les pommes (Santé Canada, 2017b).

Établies à 0.1 partie par million (ppm) dans le Règlement sur les aliments et drogues (ARLA, 2015, p.117) pour les résidus de glyphosate dans les cultures, plusieurs de ces LMR ont été modifiées au cours des années. L’Union Européenne, dont la grande majorité des LMR de 378 produits est à $0.1 \mathrm{ppm}$, a ainsi haussé les LMR de plusieurs produits agricoles, notamment les LMR de cultures GM (Tableau 1) et celles des principales cultures canadiennes.

Tableau 1: LMR de glyphosate pour les cultures principalement GM

\begin{tabular}{|l|l|l|}
\hline Cultures & $\begin{array}{l}\text { Canada } \\
\text { LMR en ppm }\end{array}$ & $\begin{array}{l}\text { Europe } \\
\text { LMR en ppm }\end{array}$ \\
\hline Maïs & 3 & $\begin{array}{l}\text { 3: Maïs sucré } \\
\text { 3: }\end{array}$ \\
\hline Soja sec & 20 & 20 \\
\hline Canola & 20 & 10 \\
\hline Coton (graines) & 40 & 10 \\
\hline Racines de betterave à sucre & 10 & 15 \\
\hline
\end{tabular}

Sources: Santé Canada, 2017b; Union Européenne, 2017 
Ainsi, comme nous l'avons souligné, l’utilisation des HBG lors de la pré-récolte pour la dessiccation des céréales et des légumineuses, a engendré une hausse importante des résidus de glyphosate sur ces aliments. Les cultures transgéniques telles que le maïs, le soja et le canola, aux taux très élevés de résidus de glyphosate, ont également des LMR nettement plus élevées que le 0.1ppm de base. Ainsi, la LMR du canola est 200 fois supérieure au Canada et 100 fois supérieure en Europe à cette LMR de base.

Encore plus élevées que les LMR canadiennes et européennes, les LMR américaines de glyphosate atteignent 100 à 300 ppm selon les types de fourrage ou encore 120 ppm pour les enveloppes de soja, 210 ppm pour les sous-produits d'égrenage du coton, 200 ppm pour la menthe verte et 30 ppm pour les céréales dont le blé...trois fois plus que les 10 ppm au Canada et en Europe (ARLA, 2015; Santé Canada, 2017b).

L'augmentation des LMR du glyphosate aux États-Unis, au Canada et en Europe date des 10 dernières années, période correspondant à une hausse majeure des épandages d’HBG. Ainsi, suite à une demande de Monsanto, les États-Unis ont augmenté, en 2013, les limites de résidus de glyphosate dans les cultures d'oléagineux incluant le soja et le lin qui sont passées de 20 ppm à 40 ppm $^{2}$ (EPA, 2013). Les LMR des patates douces et des carottes sont respectivement passées de 0.2 ppm à 3 ppm et 5 ppm, soit 15 à 25 fois supérieures aux niveaux antérieurs. Or, quand plus de 48 pour cent des importations canadiennes de cultures agricoles proviennent des ÉtatsUnis (Gouvernement du Canada, 2017), et que ces hausses semblent continues, comment ne pas s’inquiéter?

Surtout que ces LMR américaines plus élevées n’incluent pas certains métabolites de glyphosate dans leur définition de résidus. En effet, les variations de LMR entre les pays dépendent selon Santé Canada, “des profils d'emploi des pesticides” et de “l'emplacement des essais sur le terrain, utilisés pour générer les données sur les résidus chimiques” (ARLA, 2015, p.117). Les LMR, découleraient aussi des définitions différentes selon le type de culture (classique, GAT transgénique, transgénique EPSPS/GOX, denrées d’origine animale) qui varient d'un pays à l'autre. Ainsi, contrairement au Canada, les États-Unis ont exclu du calcul des résidus préoccupants, les métabolites de dégradation du glyphosate, AMPA et N-acétyle AMPA des cultures transgéniques contenant un gène GAT. Quant à l'Union européenne, elle a récemment modifié ses définitions de résidus pour tenir compte des importations en provenance des États-Unis de nouvelles variétés de soja et de maïs génétiquement modifiés contenant ce gène GAT (Ibid, pp.119-120).

Si ces LMR peuvent servir d'indicateur des niveaux de contamination, leur utilité en termes de santé publique est en réalité assez limitée. Comme pour l’ensemble des évaluations d'HBG, elles ne portent que sur le glyphosate et ne tiennent pas compte des co-formulants, pourtant jusqu’à 1000 fois plus toxiques que l’ingrédient dit actif dans 8 des 9 pesticides les plus vendus au monde (Mesnage et al., 2014). Ainsi, alors que les amines de suif polyéthoxylées

\footnotetext{
${ }^{2}$ Sauf pour les semences de canola demeurant à 20 ppm pour des raisons d’harmonisation réglementaire avec le Canada et le Codex (EPA, 2013).
} 
(POEA) ont été interdits en Europe, en 2016, en regard de leur toxicité, ils comptent parmi les multiples co-formulants d'HBG au Canada, et la récente reconduction du glyphosate pour 15 ans par l'ARLA autorise formellement jusqu'à 20 pour cent en poids de POEA dans les HBG (ARLA, 2017, p.7). L’ARLA ignore donc les POEA lorsqu'il s'agit d'évaluer les risques pour l'environnement et la santé, et d'établir des LMR.

Ces niveaux maximum de résidus de glyphosate dans les cultures ont non seulement des limites évidentes, mais elles deviennent parfaitement inutiles quand les instances réglementaires canadiennes ne se donnent pas la peine de tester les aliments afin d'en déterminer les niveaux de résidus.

\section{Aliments au glyphosate !}

Bien que le Canada ait mis en place un Programme national de surveillance des résidus chimiques et bien que l'Agence canadienne d'inspection des aliments (ACIA) ait effectué, en 2013-2014, "a total of 31306 tests for pesticide residues on 10589 monitoring samples of domestic and imported foods of animal and plant origin (2013-2014)” (ACIA, 2015, p.19), jusqu’à tout récemment, les HBG n’étaient pas inclus dans ce programme.

Ce n’est qu'en 2017, suite à des années de demandes soutenues de citoyens canadiens, dont Tony Mitra (Mitra, 2017), pour obtenir les données sur les résidus de glyphosate dans l'alimentation, que les premières données, très succinctes, ont enfin été publiées. Les constats sont troublants : sur les 3188 échantillons analysés par l’ACIA, près de 30 pour cent étaient contaminés par ces résidus (Tableau 2), soit presque la moitié (47.4 pour cent) des fèves, pois et lentilles ainsi que 36,6 pour cent des céréales, principaux produits de l'agriculture canadienne (ACIA, 2017).

Plus troublant encore, 30,7 pour cent des aliments et 31,7 pour cent des céréales pour nourrissons, une population particulièrement vulnérable aux effets délétères des substances chimiques et aux cocktails de ces substances, contenait des résidus de glyphosate (Ibid). En outre, 1.3 pour cent des échantillons dépassaient les LMR établies, dont 3.9 pour cent des échantillons de produits céréaliers, comme l’illustre le tableau ci-dessous (Ibid).

Ces résultats n’étonnent guère compte tenu des usages pré-récolte des HBG afin d’assécher les céréales, les grains et les légumineuses. Ces épandages pré-récolte, interdits en France et en Italie, ont même conduit, en avril 2018, Barilla, premier producteur mondial de pâtes alimentaires, à réduire de 35 pour cent ses commandes de blé dur canadien en raison des forts résidus de glyphosate (Vandelac et al., 2018). Aux risques d’altérer la santé s’ajoutent donc ceux d'entacher la réputation de produits canadiens et de compromettre certaines exportations. L'eau et les aliments étant les principales sources d'exposition humaine aux formulations d’HBG, ces résultats sont préoccupants pour la santé et notamment celle des nourrissons. 
Tableau 2: Résultats des analyses de détection de résidus de glyphosate dans les aliments par l’ACIA, 2015-2016

\begin{tabular}{|c|c|c|c|c|}
\hline Program & Food Type & \# Sample Tested & $\begin{array}{l}\text { \% Samples with } \\
\text { Glyphosate } \\
\text { Residues } \\
\text { Detected }\end{array}$ & $\begin{array}{c}\text { \% Samples } \\
\text { with } \\
\text { Glyphosate } \\
\text { Residues } \\
\text { above MRLs }\end{array}$ \\
\hline \multirow{2}{*}{$\begin{array}{l}\text { National } \\
\text { Chemical } \\
\text { Residue } \\
\text { Monitoring } \\
\text { Program }\end{array}$} & $\begin{array}{c}\text { Fresh fruits } \\
\text { and vegetables }\end{array}$ & 317 & $7.3 \%$ & $0 \%$ \\
\hline & $\begin{array}{l}\text { Processed } \\
\text { fruits and } \\
\text { vegetables }\end{array}$ & 165 & $12.1 \%$ & $0 \%$ \\
\hline \multirow{4}{*}{$\begin{array}{l}\text { Targeted } \\
\text { Surveys }\end{array}$} & Grain products & 869 & $36.6 \%$ & $3.9 \%$ \\
\hline & $\begin{array}{c}\text { Juice and other } \\
\text { beverages }\end{array}$ & 496 & $16.3 \%$ & $0.2 \%$ \\
\hline & $\begin{array}{l}\text { Bean/pea/lentil } \\
\text { products }\end{array}$ & 869 & $47.4 \%$ & $0.6 \%$ \\
\hline & Soy products & 263 & $11.0 \%$ & $0 \%$ \\
\hline \multirow{3}{*}{$\begin{array}{l}\text { Children's } \\
\text { Food Project }\end{array}$} & Infant cereal & 82 & $31.7 \%$ & $0 \%$ \\
\hline & Infant food & 127 & $30.7 \%$ & $0 \%$ \\
\hline & Total & 3,188 & $29.7 \%$ & $1.3 \%$ \\
\hline
\end{tabular}

Source : ACIA, 2017

\section{Du champ...au corps humain}

Alors que les HBG sont les pesticides les plus utilisés au pays depuis 2008, et que 30 pour cent des aliments analysés contiennent des résidus de glyphosate, classé comme “ probablement cancérogène pour l'humain “ par le CIRC de l'OMS (IARC, 2015), comment expliquer que le Canada n'inclut ni le glyphosate et ses métabolites, ni ses co-formulants nettement plus toxiques, dans le programme de Biosurveillance humaine des substances chimiques de l'environnement de Santé Canada (Santé Canada, 2017), mis en place depuis 2007?

Plusieurs analyses menées en Europe, montrent pourtant la présence de glyphosate dans l'organisme humain. En France, l'analyse d'échantillons d'urine de 30 personnes provenant de divers milieux et ayant des régimes alimentaires forts différents, a révélé que 100 pour cent des échantillons contenaient du glyphosate (Générations Futures, 2017). De plus, la concentration moyenne de glyphosate trouvée était de 12,5 fois la concentration maximale admissible pour un pesticide dans l'eau potable en Europe $(0.1 \mathrm{ng} / \mathrm{ml})$ (Ibid, p.7). Ces résultats rejoignent ceux de 
deux autres études réalisées en Allemagne et sur des eurodéputés de plusieurs pays européens (Ibid, pp.8-9), révélant ainsi l'ampleur de l’exposition de la population aux HBG.

Ces études, dans des pays où les usages d'HBG et les normes sont pourtant nettement moindre qu’au Canada, mériteraient sans doute d’être répétées au Québec et au Canada, compte tenu notamment des effets de perturbations endocriniennes des HBG à de très faibles concentrations (Benachour et al., 2007; Gasnier et al., 2009; Richard et al., 2005).

D’autant plus que la première étude de toxicologie générale indépendante sur les effets chroniques à long terme des HBG, réalisée sur la vie entière de 200 rats pendant 2 ans, a mis en évidence les effets toxiques du maïs génétiquement modifié NK603 (tolérant au Roundup) et du Roundup dans l'eau à des doses aussi faibles que $0.1 \mathrm{ppb}$ (soit $0.1 \mu \mathrm{g} / \mathrm{L}$, la norme européenne). Il provoquerait donc des tumeurs ainsi qu'une toxicité au niveau du foie et des reins (Séralini et al. 2014a). Que doit-on alors penser des recommandations canadiennes qui établissent les seuils de glyphosate dans l'eau potable à $280 \mu \mathrm{g} / \mathrm{L}$, soit 2,800 fois de plus que la norme européenne fixée à 0.1 $\mu \mathrm{g} / \mathrm{L}$ ? (Santé Canada, 2017c; AIDA, 2017)

Alors que les expositions aux HBG de la population canadienne, et celles des populations vulnérables, ne font l'objet d'aucun suivi, comment les instances publiques canadiennes peuventelles prétendre protéger la santé de la population? Pensent-elles pouvoir se dédouaner d’éventuels problèmes sanitaires qui y seraient liés en omettant d'analyser les formulations commerciales complètes de ces pesticides et en ignorant l'incontournable mise à jour des normes canadiennes de glyphosate dans l'eau potable à la lumière des normes européennes ?

Rappelons que le rapport des Nations Unies sur le Droit à l'alimentation (2017) souligne que "l’opinion publique reste encore insuffisamment sensibilisée aux dangers liés à certains pesticides,” ajoutant que “cette situation est aggravée par les efforts que déploient les fabricants pour minimiser les dommages causés, ainsi que par certains gouvernements complaisants qui avancent fréquemment l'argument fallacieux selon lequel la législation et les cadres réglementaires existants offrent une protection suffisante” (p.25). Cela ne rappelle-t-il pas la rhétorique utilisée par le gouvernement canadien pour affirmer l'innocuité des HBG, les autoriser jusqu'en 2032 et ignorer les 46 pesticides encore autorisées au Canada mais interdits presque partout ailleurs en raison de leur toxicité (Angot et al., 2017).

\section{"An apple a day keeps the doctor away?"}

L’étroite conception de la santé et de la salubrité des aliments, souvent réduite à la valeur nutritionnelle des aliments, participerait-elle d'un certain aveuglement volontaire des instances publiques au sujet des pesticides? Ainsi, dans son projet de politique bioalimentaire, le Québec réduit les enjeux de santé et d'alimentation aux teneurs en sel, en sucre et en gras dans les aliments, à leur valeur nutritive, aux toxi-infections et aux allergies, tout en évacuant complètement la question des résidus de pesticides qu'il renvoie aux normes établies par le gouvernement fédéral (MAPAQ, 2016), alors qu’il a toute la latitude pour être plus exigeant. 
Quant aux préoccupations sanitaires envers les agriculteurs et employés du secteur agricole, elles se résument à la santé psychologique tout en négligeant les risques sanitaires associés aux expositions aux pesticides des agriculteurs, de leur famille et des employés (MAPAQ, 2016b), notamment certaines maladies professionnelles, dont la maladie de Parkinson, désormais officiellement reconnue en France (Bolis, 2012) ou encore, les impacts neurologiques chez les enfants exposés in-utéro aux pesticides organophosphorés (Bouchard et al., 2011).

Le sondage auprès des Canadiens du Gouvernement du Canada (2017a), va même jusqu’à réduire le thème “Améliorer la salubrité des aliments et la santé” à la simple perspective “d’accroître la capacité des Canadiens de faire des choix alimentaires sains” via notamment "la promotion d'une vie saine”, sans égards, ni à la pauvreté endémique, ni aux déserts alimentaires, ni aux très hauts niveaux tolérés d’HBG dans l'eau, ni aux résidus de pesticides et ni à l'exposition croissante des populations aux pesticides...

Quant à l’objectif, “d’empêcher les produits alimentaires portant des étiquettes trompeuses...d'entrer sur le marché”, on croit rêver... Quelle ironie de la part d'un gouvernement qui refuse, depuis des années, l'étiquetage des OGM, en dépit des pétitions signées par des dizaines de milliers de citoyens, et en dépit des nombreux sondages révélant, comme celui de 2016, une "profonde aversion des consommateurs canadiens pour les aliments génétiquement modifiés” et un appui de 78 pour cent des participants à l'étiquetage obligatoire des OGM dans les aliments (Bérubé, 2016). D’ailleurs “82 pour cent des participants à cette étude avouent être préoccupés par l'utilisation d'herbicides et de pesticides et 80 pour cent par celle d'antibiotiques et d'hormones de croissance en élevage” (Ibid.). Que le Canada, tout premier pays au monde à mettre en marché un animal transgénique, à savoir un saumon GM, sans étiquetage, ni filière, bref à l'insu de la population et à raison de 4.7 tonnes déjà en 2017, prétende s'inquiéter d'étiquettes trompeuses, laisse sans voix.

Dans ce contexte, comment croire aux nobles objectifs d'une politique alimentaire visant à ce que les aliments soient “aussi sains que possible” sans définir ce qu’elle entend par “sains”...ni d'ailleurs par “autant que possible”? La qualité nutritionnelle des aliments, n’est-elle pas en lien direct avec la qualité des sols et la maturité des fruits et des légumes, qui sont tous deux en chute libre depuis les dernières décennies, notamment à cause de l'appauvrissement des sols, gavés d’intrants chimiques et de l'allongement des distances entre la production et la consommation?

Dans la même veine, comment prétendre avoir pour objectifs de prévenir et de diminuer l'obésité et les maladies chroniques, en reportant l'essentiel de la responsabilité sur les choix alimentaires des individus, sans pointer les pratiques de l'agro-industrie largement responsable en amont et en aval de tels problèmes chroniques. En effet, outre les excédents de gras trans, de sel et de sucre, nombre de substances liées à l'industrie agroalimentaire, tels les phtalates ou encore le Bisphénol A encore utilisé au Canada, contrairement à la France, comme enduit interne des boîtes de conserve notamment, ainsi que plusieurs pesticides aux effets reconnus de 
perturbation endocrinienne dont les HBG, contribuent à "l'épidémie de maladies chroniques ”3 (Cicolella, 2013). Rappelons que plusieurs études scientifiques témoignent de la contribution des perturbateurs endocriniens aux maladies chroniques, notamment aux maladies métaboliques (obésité et diabète de type 2), mais aussi aux cancers hormonaux-dépendants, à la baisse de la spermatogénèse, à la hausse des malformations congénitales et aux troubles du spectre de l’autisme (Colborn. et al, 1996; Myers et al., 2016; Vandelac \& Bacon, 1999).

La politique alimentaire canadienne osera-t-elle laisser ainsi dans l'ombre la charge de substances chimiques dans les aliments et dans l'eau ainsi que leurs effets cocktails dans toute la chaîne alimentaire? Cela est paradoxal quand on sait qu'Ottawa a souvent été, depuis le Rapport Lalonde de 1974 et les approches écosanté des dernières années du CRDI, à l'avant-garde internationale en matière d'élaboration de modèles de santé globale. Comment comprendre alors que cette future politique alimentaire canadienne présente la santé comme un simple “ choix individuel ", faisant ainsi abstraction de 60 ans de débats et de réflexions, en plus de passer sous silence les inquiétudes légitimes de la population quant aux impacts des pesticides et sans prendre des mesures essentielles pour réduire substantiellement l’usage des pesticides.

Dans un contexte où la population se nourrit et vit désormais dans une véritable "soupe chimique”, les autorités publiques ne peuvent continuer de nier les liens entre les atteintes à la faune et à la flore et les actuels problèmes sanitaires aux proportions épidémiques. Alors que, depuis 2008, la presque totalité des semences de maïs et la moitié des semences de soya au Québec sont enrobées de néonicotinoïdes (Champagne, 2017), des pesticides aux conséquences dramatiques sur les pollinisateurs et la biodiversité, Jean-Marc Bonmatin, écotoxicologue et vice-président du Groupe de travail sur les pesticides systémiques qui a rendu public, à Ottawa, en septembre 2017, un rapport sur les insecticides néonicotinoïdes (Task Force, 2015), souligne:

à part les venins foudroyants de certains animaux, ils présentent des niveaux de toxicité jamais égalés. Ils sont plus de 5000 fois plus toxiques que ne l'était le DDT dans les années 1970, par exemple. Comment pouvez-vous imaginer que, s'ils tuent tous les invertébrés, ils soient inoffensifs pour l'humain? (Champagne, 2017)

Dans le cas des HBG, comment accepter que leur ré-homologation pour 15 ans repose sur des bases scientifiques aussi inadéquates que celles de l'évaluation des impacts du glyphosate réalisée par l'ARLA au gouvernement canadien?

\footnotetext{
${ }^{3}$ Les impacts monétaires de ces maladies et troubles chroniques plus spécifiquement attribuables aux PE (obésité, diabète, troubles de la fertilité et neurocomportementaux) et dans 80 pour cent des cas à des pesticides, ont été estimés en Europe entre 157 et 270 milliards d'euros par an, soit entre 1,23 pour cent et 2 pour cent du PIB européen annuel (Trasande et al., 2015).
} 


\section{Insuffisances des dispositifs d'évaluation et d'encadrement des pesticides}

Comme en témoigne le scandale des Monsanto Papers, ces modalités d'homologation, souvent sous influence, reposent sur des bases scientifiques parfois très discutables. Mais dans le cas du document Glyphosate: Projet de décision de réévaluation PRVD2015-01 de l'ARLA (2015), censé fonder la décision canadienne, ce document, au chapitre de la santé, est si daté, si partiel et partial que sa crédibilité en est complètement minée (Vandelac \& Bacon, 2017). Ainsi, le volet toxicologique s’appuie sur 125 références, dont 118 provenant de l'industrie et donc non publiées, et sur 7 autres non identifiables, alors que l'examen des risques professionnels repose sur 9 documents, dont l'un venant de l'industrie et 7 autres non publiés, et que l'évaluation des risques alimentaires repose à 98 pour cent (340 références sur 347) sur les écrits de l’industrie agrochimique dont la très grande majorité date d'avant l'an 2000. Or, 68 pour cent des études scientifiques sur le glyphosate, publiées dans Pubmed (US National Library of Medicine), ont été produites au cours des 10 dernières années !

Ajoutons que l'ARLA conclue dans son évaluation dite “ scientifique ” du glyphosate, qu'il faut modifier les étiquettes des produits contenant du glyphosate afin d’ajouter que "Ce produit est TOXIQUE pour les végétaux terrestres non ciblés” et...“pour les organismes aquatiques”. Néanmoins, elle continue d’affirmer que “ Les produits contenant du glyphosate ne devraient pas poser de risques préoccupants pour l’environnement lorsqu’ils sont utilisés conformément au mode d’emploi proposé sur l'étiquette”, ajoutant même qu' “Il est peu probable que les produits contenant du glyphosate nuisent à la santé humaine s’ils sont utilisés conformément au mode d'emploi figurant sur leur étiquette” (ARLA, 2017, pp. 4, 7 et 83). Dans cet étrange raisonnement, l'étiquette ferait figure de "bouclier magique” non pas pour garantir l'innocuité des HBG, mais manifestement pour tenter de dédouaner les firmes et les pouvoirs publics de leurs responsabilités, alors imputées aux seuls utilisateurs de pesticides. Cette modification mineure de l'étiquetage des HBG, faisant porter l'essentiel des problèmes de santé et d'environnement sur les agriculteurs, leurs familles, les travailleurs agricoles et les consommateurs, ne tient-elle pas alors d'une manœuvre perverse?

En raison des très sérieuses lacunes et omissions dans l'évaluation du glyphosate et des HBG, plusieurs avis d'objection (Equiterre et al., 2017; Vandelac \& Bacon, 2017) envoyés au gouvernement canadien, en juin 2017, ont demandé à la Ministre de la santé, la création d’un comité d'examen indépendant conformément au paragraphe 35 (3) de la Loi canadienne sur les produits antiparasitaires. Prétendre que les HBG n’ont aucun impact sur la santé et fonder la décision de les ré-homologuer jusqu'en 2032, essentiellement sur la base de documents non publiés de l'industrie, en l'absence d'un examen rigoureux de la littérature scientifique indépendante, tout en passant sous silence les tricheries et les manipulations révélées par les Monsanto Papers, est en effet indigne d’autorités réglementaires responsables. 


\section{Une agriculture et une alimentation sevrées de leur dépendance aux pesticides?}

L'élaboration de politiques alimentaires au Canada et au Québec devrait constituer un moment clé pour sortir de l’infernal engrenage des pesticides et protéger la qualité des sols, de l’eau, de l'air, des aliments et de la santé tout en assurant la pérennité d'une agriculture viable permettant aux agriculteurs de nourrir le monde tout en répondant aux défis posés par les crises combinées du climat, de la biodiversité et des évènements climatiques majeurs.

Mais, cela implique de s’attaquer aux facteurs structurels qui en sont largement responsables et notamment de s'intéresser aux différentes formes de soutien public offertes aux producteurs agricoles. Or, au Canada, selon de récentes données de l’OCDE, ces aides étaient 4 fois plus importantes il y a 30 ans, alors qu'aux États-Unis, en Europe et dans les pays de l’OCDE, cette baisse n’a été que de moitié (Desrosiers, 2018). En outre, ces soutiens publics aux producteurs agricoles au Canada, de l'ordre de 9.3 pour cent des recettes agricoles brutes au cours des 3 dernières années, sont deux fois plus faibles que ceux de la moyenne des pays développés (18,2 pour cent) et de l’Union Européenne (19,3 pour cent) et ils sont à des lieux du Japon (46 pour cent) ou encore de l'Islande (57.6 pour cent) (Ibid.). Si une transition vers des modèles agroalimentaires alternatifs et diversifiés, axés sur un développement viable, exige le retrait des substances chimiques les plus toxiques conjuguée à une sortie progressive de productions agroalimentaires basées sur les intrants, de telles perspectives ne peuvent être envisagées sans un réinvestissement massif pour soutenir les producteurs agricoles.

Un système alimentaire résilient et diversifié pouvant répondre aux défis des crises alimentaires, de la biodiversité et du climat, ne signifie donc pas nécessairement de multiplier les “ innovations ” technoscientifiques chères, sophistiquées et brevetées du type OGM, nanotechnologies et intelligence artificielle, ni d'augmenter davantage encore l'hyper concentration horizontale et verticale du secteur agroalimentaire, où quelques firmes contrôlent plus de la moitié des semences mondiales et l'essentiel des intrants et de la R\&D (Vandelac, 2015; ETC Group, 2017, 2015). Les pouvoirs publics ne peuvent feindre d'ignorer à quel point certaines puissances économiques peuvent tout faire pour nier la toxicité de leurs produits quitte à tenter de détruire des évaluations scientifiques indépendantes et d'inféoder l'évaluation publique à leurs intérêts privés (Foucart, 2017).

En ce sens, limiter dans le monde les usages d'HBG et d'autres pesticides exige, tel que le soulignait avec raison la Rapporteuse spéciale sur le droit à l'alimentation aux Nations Unies, “une véritable volonté politique pour réévaluer et remettre en cause les intérêts corporatistes, les politiques incitatives et les relations de pouvoir qui maintiennent en place une agriculture industrielle étroitement tributaire de l’industrie agrochimique” (Nations Unies, 2017, p. 25). A cet égard, la conclusion de ce rapport est limpide : "Il est nécessaire de remettre en cause les politiques agricoles, les systèmes commerciaux et l'influence exercée par les entreprises sur les politiques publiques si nous voulons renoncer aux systèmes alimentaires industriels qui reposent sur les pesticides” (Ibid). Le défi est de taille, notamment pour le Canada. 


\section{Bibliographie}

ACIA (2015). National Chemical Residue Monitoring Program: 2013-2014 Report. Ottawa. Agence canadienne d’inspection des aliments (ACIA).

ACIA (2017). Sauvegarder grâce à la science: Dépistage du glyphosate en 2015-2016. Agence canadienne de l'inspection des aliments, Direction des sciences de l'ACIA.

AIDA (2017). Directive $n^{\circ}$ 98/83/CE du 03/11/98 relative à la qualité des eaux destinées à la consommation humaine. Consulté sur https://aida.ineris.fr/consultation_document/1017

Angot, J-L., Bastid Burdeau, G., Bellmann, C., Devienne, S., Fontagné, L., Genet, R.,...Lence, M.(2017). Rapport au Premier ministre : L'impact de l'Accord Économique et Commercial Global entre l'Union européenne et le Canada (AECG/CETA) sur l'environnement, le climat et la santé. Consulté sur http://www.gouvernement.fr/sites/default/files/document/document/2017/09/rapport_de_la _commission_devaluation_du_ceta_-_08.09.2017.pdf

ARLA (2015). Projet de décision de réévaluation PRVD2015-01. Santé Canada. Ottawa.

ARLA (2017). Glyphosate: Décision de réévaluation - RVD2017-01, Santé Canada. Ottawa.

Benhammou, F. (2009). Nourrir l'humanité: une géopolitique de l'alimentation et de l’environnement. Écologie \& Politique, 1 (38), 17-32,

Benachour, N., Sipahutar, H., Moslemi, S., Gasnier, C., Travert, C. \& Séralini, G.-E. (2007). Time- and Dose-Dependent Effects of Roundup on Human Embryonic and Placental Cells. Archives of Environmental Contamination and Toxicology, 53(1): 126-133,

Benbrook, C. (2012). Impacts of genetically engineered crops on pesticide use in the U.S., the first sixteen years. Environmental Sciences Europe, 24 (24), https://doi.org/10.1186/21904715-24-24

Benbrook, C.M. (2016). Trends in glyphosate herbicide use in the United States and globally. Environmental Sciences Europe, 28 (3). https://doi.org/10.1186/s12302-016-0070-0

Bérubé, S. (2016, 30 septembre). Les Canadiens veulent l'étiquetage des aliments OGM. La Presse, Consulté sur http://www.lapresse.ca/actualites/sante/201609/30/01-5025987-lescanadiens-veulent-letiquetage-des-aliments-ogm.php

Bolis, A. (2012, 9 mai). Le lien entre la maladie de Parkinson et les pesticides officiellement reconnu. Le Monde, Consulté sur http://www.lemonde.fr/planete/article/2012/05/09/le-lienentre-la-maladie-de-parkinson-et-les-pesticides-officiellementreconnu_1698543_3244.html 
Bouchard M.F., Chevrier, J., Harley, K.J. \& al. (2011). Prenatal Exposure to Organophosphate Pesticides and IQ in 7-Year-Old Children, Environmental Health Perspectives, 119(8), 1189-1195. doi:10.1289/ehp.1003185

Carson, R. (1962). Silent Spring. Boston: Houghton Miffin.

Cicolella, A. (2013). Toxique planète, Le scandale invisible des maladies chroniques. Paris: Seuil/Anthropocène.

Champagne, S. R. (2017, 19 septembre). Les pesticides “néonics” menacent les fondations de la biodiversité. Le Devoir, http://www.ledevoir.com/environnement/actualites-sur-lenvironnement/508300/les-pesticides-neonicotinoides-menacent-toute-la-biodiversite

Colborn, T., Dumanoski, D. \& Myers, J. P. (1996). Our Stolen Future. New-York: Dutton.

Conseil consultatif en matière de croissance économique (2017). Libérer le potentiel de croissance des secteurs clés. Ottawa: https://www.budget.gc.ca/aceg-ccce/pdf/key-sectorssecteurs-cles-fra.pdf

Desrosiers, É. (2018, 27 juin). Le Canada aide relativement peu et mal ses agriculteurs. Le Devoir, https://www.ledevoir.com/economie/531188/le-canada-aide-relativement-peu-et$\underline{\text { mal-ses-agriculteurs }}$

Douzelet, J., \& Séralini, G-E. (2018). Le goût des pesticides dans le vin. Arles: Actes Sud.

Équiterre, David Suzuki Foundation, Canadian Association of Physicians for the Environment, Environmental Defence \& Prevent Cancer. (2017). Joint Notice of Objection to Federal Health Minister re: PMRA Re-evaluation of Glyphosate. https://cape.ca/wpcontent/uploads/2017/06/Notice-of-Objection-Glyphosate-June-26-2017.pdf

EPA (2013). Glyphosate; Pesticide Tolerances. Federal Register. Vol. 78. No. 84. Wednesday May 1. pp. 25396-25400.

ETC Group. (2015). Breaking Bad: Big Ag Mega-Mergers in Play. Consulté sur http://www.etcgroup.org/sites/www.etcgroup.org/files/files/etc breakbad_23dec15.pdf

ETC Group. (2017). Who Will Feed Us? The Peasant Food Web vs. the Industrial Food Chain. Consulté sur http://www.etcgroup.org/sites/www.etcgroup.org/files/files/etcwhowillfeedus-english-webshare.pdf

FAO (2015). L’Agroécologie pour la sécurité alimentaire et la nutrition. Rome: FAO, http://www.fao.org/3/a-i4729f.pdf

Foucart, S. (2017, 1er octobre). L’expert doit-il être plagiaire? Le monde. 
Foucart, S. (2018, 23 juin). Glyphosate : la famille de Théo, 11 ans, exposé in utero, poursuit Monsanto. Le Monde. https://abonnes.lemonde.fr/planete/article/2018/06/23/glyphosate-lafamille-de-theo-11-ans-expose-in-utero-poursuit-monsanto_5320143_3244.html

Foucart, S. \& Horel, S. (2017, 9 novembre). Paris refuse la réautorisation du glyphosate au-delà de 3 ans, Le Monde.

Foucart, S. \& Horel, S. (2017a, 5 octobre). "Monsanto papers “, les agences sous l'influence de la firme. Le Monde.

Foucart, S. \& Horel, S. (2017b, 2 juin). “Monsanto papers “ : la bataille de l’information. Le Monde.

Foucart, S. \& Horel, S. (2017c, 1 juin). "Monsanto papers ” : la guerre du géant des pesticides contre la science. Le Monde.

4-traders (2018, 8 février). Global \$10 Billion Glyphosate Market Opportunity Analysis and Industry Forecasts Report, 2017-2022. http://www.4-traders.com/news/Global-10-BillionGlyphosate-Market-Opportunity-Analysis-and-Industry-Forecasts-Report-2017-2022-$\underline{25952620 /}$

Gasnier, C., Dumont, C., Benachour, N., Clair, E., Chagnon, M.C. \& Séralini, G.-E. (2009). Glyphosate-based herbicides are toxic and endocrine disruptors in human cell lines. Toxicology, 262(3): 184-191, 10.1016/j.tox.2009.06.006

Générations Futures (2017, avril). Quelle exposition des français au glyphosate (herbicide le plus vendu au monde)? Paris. https://www.generations-futures.fr/wpcontent/uploads/2017/04/GLYPHOSATE_1_0604172.pdf

Gillam, C. (2017). Whitewash: The Story of a Weed Killer, Cancer, and the Corruption of Science. Washington, DC: Island Press.

Gonzague, A. \& Michel, C. (2017). Glyphosate : le pire scandale sanitaire du XXIe siècle. http://tempsreel.nouvelobs.com/societe/20171003.OBS5502/glyphosate-le-pire-scandalesanitaire-du-xxie-siecle.html

Gorse, I. \& Dion S. (2007). Bilan des ventes de pesticides au Québec pour l'année 2003. Québec: Gouvernement du Québec.

Gorse, I. \& Balg C. (2012). Bilan des ventes de pesticides au Québec pour l'année 2009. Québec: Gouvernement du Québec.

Gorse, I. \& Balg C. (2014). Bilan des ventes de pesticides au Québec Année 2011. Québec : Gouvernement du Québec. 
Gouvernement du Canada (2017). Données sur le commerce en direct. Accédé le 4 mai 2017: https://www.ic.gc.ca/app/scr/tdst/tdo/crtr.html?\&productType=NAICS\&lang=fra

Gouvernement du Canada (2017a). Une politique alimentaire pour le Canada. Accédé le 31 août: https://www.canada.ca/fr/campagne/politique-alimentaire/consultation-descanadiens.html\#a1

Horel, S., \& Foucart, S. (2017, 5 octobre). Soupçons sur les substances ajoutées au glyphosate dans les "produits formulés “. Le Monde.

IARC (2015). Evaluation of glyphosate. World health organization: International agency for research on cancer.

IPES-Food (2016). From uniformity to diversity: a paradigm shift from industrial agriculture to diversified agroecological systems. International Panel of Experts on Sustainable Food systems. www.ipes-food.org

ISAAA (2016). Global Status of Commercialized Biotech/GM Crops: 2016. ISAAA Brief No. 52. NY.

Krimsky, S. \& Gillam, C. (2018). Roundup litigation discovery documents: implications for public health and journal ethics. Journal of Public Health Policy. https://doi.org/10.1057/s41271-018-0134-z

Lesnes, C. (2018, 23 juin). Premier procès du glyphosate aux États-Unis. Le Monde. https://abonnes.lemonde.fr/planete/article/2018/06/23/premier-proces-du-glyphosate-auxetats-unis_5320012_3244.html

Livesey, B. (2017, 25 juillet). Has Ottawa sold out to Big Agro and its toxic chemicals? National Observer. https://www.nationalobserver.com/2017/07/25/news/has-ottawa-sold-outbig-agro-and-its-toxic-chemicals

Mao, Q., Manservisi, F., Panzacchi, S., Mandrioli, D., Menghetti, I., Vornoli, A.,...Hu, J. (2018). The Ramazzini Institute 13-week pilot study on glyphosate and Roundup administered at human-equivalent dose to Sprague Dawley rats: effects on the microbiome. Environmental Health, 17(50). doi.org/10.1186/s12940-018-0394-x

MAPAQ (2011). Stratégie phytosanitaire québécoise en agriculture 2011-2021. Québec: Ministère de l'Agriculture, des Pêcheries et de l'Alimentation (MAPAQ). Consulté sur https://www.mapaq.gouv.qc.ca/fr/Publications/Strategie_phytosanitaire.pdf

MAPAQ (2016). À l'écoute des consommateurs d'aujourd'hui et de demain. Cahier thématique 1. Alimentation sommet 2017. Gouvernement du Québec. 
MAPAQ (2016a). Développement du potentiel de l'industrie alimentaire québécoise sur les marchés d'ici et d'ailleurs. Cahier thématique 2. Alimentation sommet 2017. Gouvernement du Québec.

MAPAQ (2016 b). Perspectives d'avenir pour les entrepreneurs agricoles et les pêcheurs. Cahier thématique 3. Alimentation sommet 2017. Gouvernement du Québec.

MAPAQ (2018). Politique Bioalimentaire 2018-2025: Alimenter notre monde. Québec : Gouvernement du Québec.

Marceau, G. (2017, 15 septembre). Le déclin des oiseaux champêtres. Radio-Canada. https://ici.radio-canada.ca/nouvelle/1055660/le-declin-des-oiseaux-champetres

McHenry, L. B. (2018). The Monsanto Papers: Poisoning the scientific well. International Journal of Risk \& Safety in Medicine, 29 (3-4),193-205.

MDDELCC (2015). Stratégie québécoise sur les pesticides 2015-2018: Agir ensemble pour protéger la santé, les pollinisateurs et l'environnement. Québec : http://www.mddelcc.gouv.qc.ca/pesticides/strategie2015-2018/strategie.pdf

MDDELCC (2016). Bilan des ventes de pesticides 2014. Milieu agricole. Ministère du Développement durable, de l'Environnement et de la Lutte contre les changements climatiques (MDDELCC). Québec.

MDDELCC (2017, septembre). Bilan des ventes de pesticides au Québec 2015. Ministère du Développement durable, de l'Environnement et de la Lutte contre les changements climatiques (MDDELCC). Québec. http://www.mddelcc.gouv.qc.ca/pesticides/bilan/index.htm

MDDLECC (2018, 19 février). Mise en œuvre de la Stratégie québécoise sur les pesticides Meilleure protection pour la santé, l'environnement et les abeilles. Communiqué de presse. Québec: Ministère du Développement durable, de l’Environnement et de la Lutte contre les changements climatiques (MDDLECC). Consulté sur http://www.mddelcc.gouv.qc.ca/infuseur/communique.asp?no=3921

Mesnage, R., Defarge, N., Spiroux de Vendômois \& J. \& Séralini, G.E. (2014). Major pesticides are more toxic to human cells than their declared active principles. BioMed Res. Int.: 179691

Mesnage R., Defarge N., Spiroux de Vendômois J., \& Séralini GE. (2015). Potential toxic effects of glyphosate and its commercial formulations below regulatory limits. Food Chem Toxicol, 84,133-53.

Mitra, T. (2017). Poison Foods of North America: Guide to navigating the glyphosate mine field in our food web (Kindle Locations 340-343). De https://www.amazon.com 
Myers, J.P., Antoniou, M.N., Blumberg, B., Carroll, L., Colborn. T., Everett, L.G.,... Benbrook, C.M. (2016). Concerns over use of glyphosate-based herbicides and risks associated with exposures: a consensus statement. Environmental Health, 15(19), 1-13. https://doi.org/10.1186/s12940-016-0117-0

Nations Unies. (2017). Rapport de la Rapporteuse spéciale sur le droit à l'alimentation. Assemblée générale. A/HRC/34/48. Conseil des droits de l’homme, Trente-quatrième session.

Neslen, A. (2017, 28 septembre). Monsanto banned from European parliament. The Guardian. https://www.theguardian.com/environment/2017/sep/28/monsanto-banned-from-europeanparliament

OECD (2013). 2013 Edition of the OECD Environmental Database: Pesticides. Organisation for Economic Co-operation and Development. Consulté sur https://stats.oecd.org/Index.aspx?DataSetCode=TAD_ENVINDIC_2013

OECD (2017). Agri-Environmental other indicators: Pesticides sales. Organisation for Economic Co-operation and Development. Consulté sur http://stats.oecd.org//Index.aspx?QueryId=79425\&lang=en

Picchi, A. (2018, 26 juin). Monsanto's Roundup weed-killer goes on trial. CBS News. Consulté sur https://www.cbsnews.com/news/monsantos-roundup-weed-killer-goes-on-trial-withbillions-at-stake/

Pretty, J. \& Pervez Bharucha, Z. (2015). Integrated Pest Management for Sustainable Intensification of Agriculture in Asia and Africa. Insects, 6, 152-182.

Richard, S., Moslemi, S., Sipahutar, H., Benachour, N. \& Séralini, G.-E. (2005). Differential effects of glyphosate and roundup on human placental cells and aromatase. Environmental Health Perspectives, 113(6), 716-720. 10.1289/ehp.7728

Robin, M-M. (2008). Le monde selon Monsanto : De la dioxine aux OGM, une multinationale qui vous veut du bien. Montréal: Éditions Stanké.

Robin, M.-M. (2018). Le Roundup face à ses juges. Montréal: Éditions Écosociété.

Santé Canada (2009). Rapport des ventes de produits antiparasitaires au Canada 2009. Gouvernement du Canada.

Santé Canada (2010a). Rapport des ventes de produits antiparasitaires au Canada 2010. Gouvernement du Canada.

Santé Canada (2010b). PMRA List of Formulants. Gouvernement du Canada. http://publications.gc.ca/collections/collection_2010/arla-pmra/H114-22-2010-eng.pdf 
Santé Canada (2011a). Rapport concernant les ventes de produits antiparasitaires en 2007 et 2008. Gouvernement du Canada.

Santé Canada (2011b). Rapport des ventes de produits antiparasitaires au Canada 2011. Gouvernement du Canada.

Santé Canada (2012). Rapport des ventes de produits antiparasitaires au Canada 2012. Gouvernement du Canada.

Santé Canada (2013).Rapport des ventes de produits antiparasitaires au Canada 2013. Gouvernement du Canada.

Santé Canada (2014). Rapport des ventes de produits antiparasitaires au Canada 2014. Gouvernement du Canada.

Santé Canada (2017, septembre). Biosurveillance humaine des substances chimiques de l'environnement. https://www.canada.ca/fr/sante-canada/services/sante-environnementmilieu-travail/contaminants-environnementaux/biosurveillance-humaine-substanceschimiques-environnement.html

Santé Canada (2017a). Rapport sur les ventes de produits antiparasitaires en 2014. Ottawa.

Santé Canada (2017b). Banque de données sur les LMR. Accédé le 27 septembre 2017. http://prrp.hc-sc.gc.ca/mrl-lrm/index-fra.php

Santé Canada (2017c). Recommandations pour la qualité de l'eau potable au Canada: Tableau sommaire. Ottawa. https://www.canada.ca/content/dam/hc-sc/migration/hc-sc/ewhsemt/alt_formats/pdf/pubs/water-eau/sum_guide-res_recom/sum_guide-res_recom-fra.pdf

Séralini, G-É. (2005). Génétiquement incorrect. Paris: Ed. Flammarion.

Séralini, G.-E. (2015). Why glyphosate is not the issue with Roundup. A short overview of 30 years of our research. The Journal of Biological Physics and Chemistry, 15 (3), 111-119.

Séralini, G.-E., Mesnage, R., Defarge, N. \& Spiroux de Vendômois, J. (2014). Conflicts of interest, confidentiality and censorship in health risk assessment: the example on an herbicide and a GMO. Environmental Sciences Europe. 26 (13). https://doi.org/10.1186/s12302-014-0013-6

Séralini, G.-E., Clair, E., Mesnage, R., Gress, S., Defarge, N., Malatesta, M., Hennequin, D. \& Spiroux de Vendômois, J. (2014a). Republished study: long-term toxicity of a Roundup herbicide and a Roundup-tolerant genetically modified maize. Environmental Sciences Europe. 26 (14). https://doi.org/10.1186/s12302-014-0014-5 
Task Force (2015). Worldwide Integrated Assessment of the Impacts of Systemic Pesticides on Biodiversity and Ecosystems. The Task Force on Systemic Pesticides. http://www.tfsp.info/assets/WIA_2015.pdf

Trasande, L., Zoeller, R.T., Hass, U., Kortenkamp, A., Grandjean, P., Myers, J.P., ...Heindel, J.J. (2015). Estimating Burden and Disease Costs of Exposure to Endocrine-Disrupting Chemicals in the European Union. The Journal of Clinical Endocrinology and Metabolism, 100, 1245-1255. doi:10.1210/jc.2014-4324

UNCCD (2017). Perspectives territoriales mondiales. Bonn: Secrétariat de la Convention des Nations Unies sur la lutte contre la désertification. https://global-land outlook.squarespace.com/the-outlook/\#the-bokk

Union Européenne (2017). Base de données européennes sur les pesticides. Consulté le 4 mai http://ec.europa.eu/food/plant/pesticides/eu-pesticides $\underline{\text { database/public/?event=pesticide.residue.CurrentMRL\&language }=F R}$

USRTK (2018). U.S. Right to Know. https://usrtk.org/

USGS (2017). Pesticide National Synthesis Project. Accédé le 29 septembre: https://water.usgs.gov/nawqa/pnsp/usage/maps/show_map.php?year=2015\&map=GLYPH OSATE\&hilo $=\mathrm{L}$

Vandelac, L. \& Bacon, M-H. (1999). Perturbateurs endocriniens et polluants organiques persistants : l’inquiétante érosion de la santé, de la fertilité et des capacités intellectuelles... Ruptures, Revue transdisciplinaire en santé. 6 (2). 237-267.

Vandelac, L. \& Bacon, M-H. (2017). Avis d’objection à la décision de réévaluation RDV2017-01 sur le Glyphosate. Présenté à l’Agence de réglementation de la lutte antiparasitaire (ARLA), Ottawa, https://cape.ca/wp-content/uploads/2018/03/5.Avis-d \%E2 \%80 \%99objection-a \%CC \%80-la-de \%CC \%81cision-de-re \%CC \%81e \%CC \%81valuationRDV2017-01-sur-le-Glyphosate-2017-Juin.pdf

Vandelac, L. (2015). Nanotechnologies et systèmes alimentaires?. Dans D. Bourg et A. Papaux (Eds). Dictionnaire de la pensée écologiste (pp. 775-778). Paris: Presses universitaires de France.

Vandelac, L. (2018). Avaler des pesticides au risque d’être avalés par notre mutisme. Dans M-M Robin. Le Roundup face à ses juges (Préface). Montréal: Écosociété.

Vandelac, L., Parent, L., Monnier, P., Comeau, A., Auger, P., Waridel, L \& Bacon, M-H. (29 juin 2018). Les herbicides à base de glyphosate en Europe et au Canada. Options politiques. Consulté sur http://policyoptions.irpp.org/fr/magazines/june-2018/lesherbicides-a-base-de-glyphosate-en-europe-et-au-canada/ 